\title{
FUENTES DE FINANCIACIÓN DE LA OBRA PÚBLICA EN LA BAHÍA DE CÁDIZ (SIGLO XVIII)
}

\author{
Juan Torrejón Chaves \\ Universidad de Cádiz
}

\section{RESUMEN}

En el trabajo se especifican los recursos financieros que se aplicaron para la realización de obras públicas en Cádiz y su bahía durante el Setecientos. Se trata de un trabajo de síntesis, fundamentado en varias investigaciones monográficas, que permite conocer con precisión, las modalidades impositivas, la practica de la recaudación tributaria, la utilización del crédito, $\mathrm{y}$ otras variadas maneras de las que se sirvió el sector público en una economía de Antiguo Régimen para sufragar sus gastos, en esta gran metrópoli mercantil de importancia fundamental en la economía española del momento. Los medios de financiación que se utilizaron fueron muy variados: consignaciones presupuestarias, arbitrios ordinarios y extraordinarios, préstamos, fondos vitalicios, donaciones, y ejecución de trabajos en condiciones muy favorables para el Estado a cambio de que se otorgasen gracias diversas a quienes los realizaban.

Palabras claves: Recursos financieros, obra pública, Cádiz, siglo XVIII.

\section{ABSTRACT}

In this paper we outline the means used in order to finance public works in Cádiz and the bay area during the 1700 s. It is a work of synthesis based on a variety of monographic research which allows us to more fully understand the tax collection system, the use of credit and the other ways by which the public sector was able to meet cost under the economy of the Old Regime in Cádiz, the great mercantile metropolis which was fundamental varied; budget allowances, ordinary and extraordinary municipal taxes, bank loans, pension funds, donations as well as the granting of state favours in exchange for work carried out.

Keywords: Financial's resources, public works, Cádiz, XVIII' ${ }^{\text {th }}$ century, 


\section{INTRODUCCIÓN}

En estas páginas se especifican los recursos financieros que se aplicaron para la realización de obras públicas en Cádiz y su bahía durante el Setecientos. Se trata de un trabajo de síntesis, fundamentado en varias investigaciones monográficas, algunas de las cuales han sido publicadas ${ }^{1}$. Con lo ya estudiado, es posible presentar una visión global del tema, que nos permite conocer con mayor precisión las modalidades impositivas, la práctica de la recaudación tributaria, la utilización del crédito, y otras variadas maneras de las que se sirvió el sector público en una economía de Antiguo Régimen para sufragar sus gastos, en un ámbito de tanta importancia económica en el momento como fue la sede que monopolizó el comercio colonial español; puerto al que se había traspasado en 1680 la cabecera de las flotas de Indias, y se trasladó en 1717 la Casa de Contratación.

Como se verá seguidamente, los medios financieros utilizados fueron muy variados: consignaciones presupuestarias, arbitrios, fondos vitalicios, préstamos, donaciones, y ejecución de trabajos en condiciones muy favorables para el Estado, a cambio de que se otorgasen gracias diversas a quienes los realizaban ${ }^{2}$. Aún así el panorama no se completa del todo. Hubiera sido necesario tratar además de la venta en ocasiones de propiedades públicas, la formación de "fondillos" diversos, las subastas de materiales excluidos, y otros mecanismos que aquí se han obviado por la limitación inherente a un trabajo de esta naturaleza. Tal complejidad en las formas de obtención de los recursos financieros, es un claro exponente de la manifiesta incapacidad de la Hacienda del absolutismo para obtener los ingresos que precisaba, en particular durante las coyunturas bélicas cuando

\footnotetext{
'TORREJÓN CHAVES, Juan: La Nueva Población de San Carlos en la Isla de León (1774-1806). Madıid, Ministerio de Defensa, 1992; CANO RÉVORA, Gloria y TORREJÓN CHAVES, Juan: "La ciudad de Cádiz y su acceso terrestre: Aspectos financieros de la obra del arrecife (1759-1792)", en Cuadernos de llustración y Romanticismo 11․ 3, pp. 43-55. Cádiz, Servicio de Publicaciones de la Universidad de Cádiz, 1992; CANO RÉVORA, Gloria y TORREJÓN CHAVES, Juan: "Arbitrios y Fortificación: la financiación de las murallas de la ciudad de Cádiz en el siglo XVIII", en FORTEA PEREZ, José Ignacio y CREMADES GRIÑAN, Carmen María: Politica y Hacienda en el Antiguo Régimen, Vol. I, pp. 185-202. Murcia, Secretariado de Publicaciones de la Universidad de Muicia, 1993; TORREJÓN CHAVES, JUAN: "Consideración y tratamiento histórico del espacio físico litoral. Cádiz y la Muralla del Sur", en Actas del $14^{\circ}$ Curso de Verano de San Roque: Medio ambiente en la ordenación del espacio litoral, pp. 73-98. Cádiz, Servicio de Publicaciones de la Universidad de Cádiz, 1994; TORREJÓN CHAVES, Juan y CANO RÉVORA, Gloria: "Vinos y Fiscalidad en el Cádiz del siglo XVIII", en Actas del I Symposio de Ia Asociación Internacional de Historia y Civilización de la Vid y el Vino, celebrado en El Puerto de Santa María en marzo de 1999 (en fase de edición).

${ }^{2}$ COMín, Francisco: Historia de ta Hacienda pública, II. España (1808-1995). Barcelona, Crítica, 1996. Cuando el autor trata sobre "El descalabro de la fiscalidad absolutista y los orígenes de la Hacienda liberal (1808-1844)" advierte la incoherencia de los gravámenes en la fiscalidad del Antiguo Régimen, su elevado número y sus escasos rendimientos, señalando que cuando se querian aliviar las penurias de la Hacienda, todavia se establecian nuevas contribuciones, complicando aún más el cuadro tributario (p. 72).
} 
los gastos se disparaban. Francisco Comin ha precisado que, en la España anterior a la reforma de 1845 , más que de un sistema tributario habria que hablar de un mosaico fiscal, en el que unos tributos se añadian a otros sin más justificación que la de allegar recursos a una Tesorería hambrienta ${ }^{3}$.

Los estudios particulares que han servido para componer lo fundamental de este texto son los relativos a la construcción, reparación y mantenimiento de las fortificaciones de Cádiz; la ejecución del nuevo arrecife que comunicó esta ciudad con la Isla de León; el complejo proceso constructivo de una nueva población de carácter marítimo en la Isla de León, que recibió el nombre de "San Carlos"; y la formación de una "playa artificial" para la defensa de la muralla del Sur en el frente de Vendaval de la plaza de Cádiz.

A) El amurallamiento representó la obra pública más importante que se efectuó en Cádiz a lo largo del siglo XVIII. Si bien el proceso fortificador moderno se había iniciado y desarrollado en las dos centurias anteriores, fue precisamente durante el Setecientos cuando se terminó por configurar la ciudad como gran plaza fuerte, convirtiéndose en una de las piezas claves del sistema defensivo del Imperio español. Las sumas que se invirtieron en las murallas fueron elevadísimas y provinieron principalmente de los arbitrios destinados a las fortificaciones denominados "ordinarios"; a los que se unieron, en momentos determinados, los arbitrios "extraordinarios", y otros ingresos de menor importancia como los producidos por arrendamientos de almacenes de las murallas y de diversas casillas.

Una idea de las grandes cantidades que se destinaron a las fortificaciones gaditanas nos lo proporciona la Relación efectuada por la Contaduria de todos los arbitrios que se han aplicado a las murallas desde mediados de agosto de 1696, hasta finales del año 1716, en la que se especifica un monto total de 373 cuentos y 871.905 maravedíes (mrs.) ${ }^{4}$.

B) La única comunicación por tierra que poseía la ciudad de Cádiz era un arrecife que la conectaba con la Isla de León. Se trataba de un camino firme y empedrado que, después de ser arrasado por el enorme aguaje que provocó el maremoto de $1^{\circ}$ de noviembre de 1755 , fue proyectado de nuevo con una mejor traza; sacándose su obra a concurso público por el sistema de asiento. Los trabajos por cuenta del asentista comenzaron el $1^{\circ}$ de abril de 1759 y continuaron en sus manos hasta finalizar agosto de 1770 , cuando se suspendió el asiento y los trabajos siguieron por administración. En estos once años largos el contratista

' COMLN, Francisco: Hacienda y Economta en la España Contemporánea (1800-1936). Madrid, Ministerio de Economía y Hacienda / Instituto de Estudios Fiscales. Volumen I, p. 76.

'Archivo Histórico Municipal de Cádiz (A.H.M.C.), Libro de Cabildos nº 10.098 , fols. 47-49 v. 
había construido por valor de 17.488 .403 reales de vellón (rs. vn.) y 13 mrs., recibiendo a cambio 12.246 .718 rs. vn. y $6 \mathrm{mrs}$.

A cambio de la construcción del nuevo arrecife, y en conformidad con las condiciones pactadas, que habían fijado los ingenieros militares, el asentista debía recibir una cantidad fija mensual de 83.333 rs. vn. y $11 \mathrm{mrs}$, que conformarían al año 1.000 .000 rs. yn., los cuales se obtendrían de dos arbitrios ordinarios: $98 \mathrm{mrs}$. en cada arroba de vino del que entrase en la ciudad, y el $1 / 2$ por ciento de Aduana; entregándose al propio contratista el cobro de los mismos, como garantía de la percepción de tales tributos.

C) La nueva población de San Carlos fue un ambicioso proyecto que se inició en 1774 , con el que se pretendía levantar una ciudad "ex novo" para albergar al más importante de los Departamentos Marítimos de la España del siglo XVIII. Éste había sido creado en Cádiz en 1717, coincidiendo con el traslado de la Casa de Contratación, y permaneció en la ciudad de Hércules hasta 1776, cuando se traspasó a la entonces villa de la Real Isla de León, donde los distintos cuerpos y dependencias de la Marina se aposentaron de manera provisional, en espera de contar con instalaciones apropiadas. Para ello se adquirieron tierras en la cercanía del Real Arsenal de la Carraca, y comenzó un ambicioso y complejo proceso constructivo que fue ejecutado sólo en parte, en el que intervinieron miembros de los cuerpos de Ingenieros del Ejército y de Ingenieros de Marina, así como otros técnicos y arquitectos de renombre. Cuando las obras se paralizaron en los inicios del siglo XIX, únicamente se habían levantado algunos edificios de la que debía haber sido la más compleja e importante de todas las nuevas poblaciones españolas de carácter marítimo, de los reinados de Carlos III y Carlos IV.

D) Las intervenciones en el frente del Sur de la ciudad de Cádiz fueron constantes a lo Iargo del Setecientos. Esta muralla, que se iniciaba en el baluarte de los Mártires para finalizar en el de San Roque, se denominaba de Vendaval y se caracterizó por sus continuados deterioros en los temporales de invierno; lo que obligaba a frecuentes y costosas reparaciones, que eran proyectadas y dirigidas por los ingenieros del Ejército. Ante los reiterados y elevados gastos que representaba el mantenimiento de este muro, que cumplía -más que militar- sobre todo una función preservadora de la integridad física de la ciudad, y después del rotundo éxito que había logrado el ingeniero de Marina, Tomás Muñoz, con la construcción de los diques de carenar en seco del Real Arsenal de la Carraca, se aceptó su proyecto de levantar en este frente del Sur una "playa artificial" que, deteniendo la fuerza del mar, solventara definitivamente el problema. Los trabajos comenzaron en los primeros días de junio de 1787 y se dieron por finalizados el 6 de enero de 1792. Los gastos se presupuestaron inicialmente en 19.880 .985 
rs. vn.; pero los costes -incluidos los correspondientes a las posteriores recomposiciones de los destrozos causados por las tempestades- se elevaron a mediados de febrero de 1796 a 39.271 .020 rs. vn. y $10 \mathrm{mrs}$.

Cuando se pensaba en la imposición de las cargas para esta obra, se debatió si su principal fin era la conservación de la ciudad y de sus vecinos, o la defensa de la plaza. Y al entenderse desde el Gobiemo que el objeto de la misma no era la defensa militar, sino la preservación física de la ciudad de los embates del mar, los arbitrios extraordinarios recayeron sobre el vecindario.

En las actuaciones referidas (letras A-D), las desviaciones presupuestarias estuvieron muy presentes, al hallarse generalmente las previsiones de gastos por debajo de los realmente acometidos; teniéndose que acudir a recursos muy variados para equilibrar los presupuestos.

Al recibirse nuevos fondos, se procedía del modo siguiente para la liquidación total o parcial de los débitos:

$1^{\circ}$. Se abonaban a los asentistas las certificaciones de gastos ordinarios.

$2^{\circ}$. Se pagaba a los proveedores que surtían artículos de acopio indispensables, independientes del ramo de los asientos (cal, yeso, ladrillos, clavazones, herramientas, etc.).

$3^{\circ}$. Se liquidaban los importes de las certificaciones de gastos extraordinarios.

$4^{\circ}$. Se satisfacían los jornales devengados por los trabajadores, cuando las obras corrían por administración.

Pero cuando no llegaban recursos para cumplir con las obligaciones asumidas en los contratos de obras y de aprovisionamientos, los directores de las obras tenían que ingeniárselas para que las actividades no se paralizasen, presentando alternativas muy variadas a los acreedores. Incluso se llegó a poner como condición, para la consecución de un nuevo contrato de distinta naturaleza, que el asentista condonase la deuda que la administración mantenía con él por un asiento de obras en curso. Eso ocurrió con Francisco Zimbrelo, el cual se ocupó del mantenimiento de los enfermos y del personal adscrito al servicio de los hospitales de la Marina en la ciudad de Cádiz y en el Real arsenal de La Carraca, a partir de 1793. Entre las condiciones deI contrato, se le impuso la obligación de renunciar al derecho que tenía de percibir algo más de un millón rs. vn. por el asiento de cantería para las obras de la nueva población de San Carlos. 


\section{CONSIGNACIONES PRESUPUESTARIAS ORDINARIAS Y EXTRAORDINARIAS}

Estas consignaciones fueron el medio principal de que se valió la Marina para sus obras de San Carlos, hasta que comenzó el grave deterioro de la Real Hacienda en la última década del siglo XVIII, una época que se caracterizó por los crecientes gastos estatales, teniéndose que buscar medios alternativos para finalizar las obras ya comenzadas, o iniciar y concluir aquéllas que resultaban tan necesarias.

En noviembre de 1774, Julián de Arriaga -Secretario de Estado y del Despacho Universal de Marina e Indias- fue informado por el Rey de que la Marina dispondría de una asignación extraordinaria anual de 9.000 .000 millones rs. vn. para obras en los Departamentos: 4 para Cádiz, 3 para El Ferrol y 2 para Cartagena. De la dotación concedida a Cádiz, se pensó disponer un millón para la construcción de un dique de carenar en seco para navíos de línea en el arsenal de La Carraca, que hacía mucha falta, y los otros 3 para la adquisición de terrenos y el levantamiento de las edificaciones que albergasen convenientemente al Departamento.

El 7 de Abril de 1775 se adquinieron al Duque de Arcos 171 y media aranzadas, por las que se le abonaron $580.000 \mathrm{rs}$ vn. Sirvió como fundamento para acordar el precio, el cálculo del aprovechamiento medio de estas tierras en los cinco años anteriores ${ }^{5}$. La operación fue muy favorable para la Real Hacienda, ya que el quinquenio 1771-1775 fue de contracción económica, anómalo en el reinado de Carlos III (1759-1788) que se desenvolvió en una coyuntura alcista, sobre todo a partir de 1775 , y particularmente desde la guerra contra Gran Bretaña (1779-1783).

Los pagos se efectuaban con cargo a la Consignación del ramo de obras proyectadas para el servicio de Marina en las inmediaciones de la Villa de la Rl. Isla de León. Y era usual en la Armada del momento que estas consignaciones extraordinarias para obras o asuntos preferentes, se colocasen separadas en arcas de tres llaves, una de las cuales se hallaba en posesión del Director o responsable de los trabajos. Se pretendía, por medio de la custodia directa por parte de los ingenieros-comandantes que no se desviasen de su objeto los fondos destinados al mismo; cosa que era muy frecuente en otras partidas del presupuesto de Marina en los Departamentos, en los cuales los Intendentes desviaban las consignaciones de sus destinos originarios, en situaciones de apuros.

\footnotetext{
"Archivo General de Simaneas (A.G.S.), Secretaría de Marina, leg. 352 y 357 . Ibidem, Secretaría y Superintendencia de Hacienda, leg. 50.
} 
Por Real Orden de 29 de agosto de 1776 se consignaron 2.000 .000 rs. vn. más para estas obras, que se agotaron en agosto de 1779; señalándose entonces una cantidad fija mensual de $100.000 \mathrm{rs}$. vn. A partir del presupuesto general de gastos de Marina para 1785 , se incluyeron 2.400 .000 rs. vn. anuales, a razón de 200.000 mensuales de consignación ordinaria para la nueva población ${ }^{6}$. Pero esto no debe llevarnos a pensar que estas cantidades eran recibidas puntualmente en las obras. Así, durante el conflicto con la Gran Bretaña (1779-1783) sus fondos fueron desviados hacia las necesidades más perentorias del Departamento que la guerra imponía, recibiendo asentistas y proveedores certificaciones pendientes de pago. Cuando se firmó la Paz de Versalles, al asentista del desmonte de los terrenos se debían 1.394 .424 rs. vn. y $24 \mathrm{mrs}$. por obra realizada.

\section{2.- ARBITRIOS ORDINARIOS Y EXTRAORDINARIOS}

Los arbitrios destinados para las fortificaciones lo eran para las construcciones nuevas, los mantenimientos y las reparaciones de las murallas de la ciudad de Cádiz, tanto en los frentes de mar como en el de tierra, sus terraplenes y explanadas para la artillería, los baluartes y castillos, las entradas cubiertas, los puentes levadizos y -en general - todo lo que concernía directa y estrictamente a la defensa de la plaza fuerte. $Y$ además, los cuarteles, el arrecife que iba a la Isla de León, así como los gastos que comportaba el aparato administrativo de las fortificaciones. También se soportaba el pago de la casa del Teniente de Rey, quien presidía, en calidad de sustituto, la Junta de Fortificaciones.

Los cuerpos de guardia, almacenes, cobertizos para la artillería, y obras semejantes, eran costeadas por cuenta de la Real Hacienda. Mientras que de los bienes de propios de la ciudad se atendían las puertas del recinto, accesos y empedrados, las estacadas y los rastrillos exteriores, y los puentes fijos, así como el muelle.

También se hallaba a cargo de la Junta de Fortificaciones el arrecife que unía la ciudad de Cádiz con la villa de la Real Isla de León, ya referido y que precisaba continuados trabajos para su conservación, en particular los constantes desarenos. Los fondos para su reconstrucción y cuidados se sacaban de los arbitrios ordinarios que ingresaba la citada Junta. Cuando los gastos se dispararon para la muralla del Sur, y se ordenó -en agosto de 1789- destinar a estas obras todos los

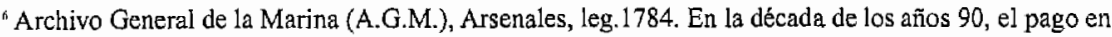
sueldos y gratificaciones que recibía mensualmente el personal directivo y técnico de San Carlos hubo momentos que se elevó a 84.265 rs. vn., de los cuales 30,000 correspondían al Director.
} 
fondos de fortificación, se impuso un peazgo para el mantenimiento de este arrecife, debiendo pagar $1 / 2 \mathrm{rl}$. vn. cada calesa o calesín, y un rl. vn. cada carro, coche o berlina de camino que transitara por el mismo.

\subsection{ARBITRIOS ORDINARIOS}

Con anterioridad al siglo XVIII, se aplicaban al amurallamiento de la plaza de Cádiz 3.000 ducados cada año que tenía la ciudad concedidos al respecto, y que se sacaban del rendimiento de diversos arbitrios que fueron impuestos para el reintegro de los donativos con que se había auxiliado al Rey en varias ocasiones?; para el pago de 70.000 escudos que relevaron al vecindario gaditano de la contribución de medio año de los alquileres de sus casas; y de los 80.250 escudos para la restitución a esta ciudad y permanencia en la misma del Juzgado y Tabla de Indias, y repartimiento entre sus vecinos del Tercio de Toneladas ${ }^{8}$.

Los arbitrios que se habían concedido para el pago de los referidos donativos, por Real facultad de I5 de febrero de I665, fueron:

- E1 1\% en Ias mercaderías que se despachaban de entrada y salida en la Real Aduana de esta ciudad, y que fue denominado "antiguo".

-2 reales en cada arroba de vino que entrase en corambre para colana.

E1 27 de mayo de 1669, se unió a los anteriores:

- 3 ducados en cada bota de vino de treinta arrobas.

Y diez años más tarde, otro Despacho de 22 de septiembre de 1679, otorgó además:

- 2 ducados de plata en tonelada de las que por tercio tocaban a la ciudad de Cádiz en las flotas de Nueva España y Tierra Firme, que se exigió hasta $1720^{\circ}$.

El asunto se mantuvo así hasta el cabildo municipal que se celebró el 3 de agosto de 1684, en el que se acordó -a instancia del entonces Procurador mayor Juan Infante de Olivares, y para remediar el evidente riesgo a que estaba expues-

\footnotetext{
' La conquista de Portugal; deterninadas asistencias de pago a las trapas que habian legado de Italia y Alemania; con motivo de la guerra de Sicilia; y en el socorro de Orán.

"A.H.M.C., Libro de Cabildo n". 10.098, fol. 47.

"A.G.S., Guerra Antigua, leg. 3.099.
} 
ta de inundarse y perderse una Plaza de tanta consequencia, por ser de las mas principales, y la llave y seguridad de esta Monarchia- solicitar al Monarca la capacidad de imponer para la construcción de las murallas, que deberían comprender toda la circunvalación de la plaza de forma que el agua del mar hallase por todas partes la resistencia suficiente para no pasar adelante los arbitrios siguientes:

- Un octavo por cada arroba de vino.

- Un octavo en la arroba de aceite.

- Medio octavo en la arroba de vinagre.

- Dos reales en cada arroba de cerveza.

Mas parece que lo solicitado no fue concedido hasta un Real Despacho de 14 de julio de 1693 , comenzando la exacción a partir del $1^{\circ}$ de septiembre de tal año.

El 3 de abril de 1699 cesó el octavo que se cobraba por el aceite, pero se sumó a los arbitrios anteriores el $1 / 2$ por ciento que se cobraba en la Real Aduana sobre las mercancías desde 1602.

Una Real provisión de 24 de julio de 1699 , unió a lo antecedente las Penas de Cámara, cuyo montante era poco significativo.

Ya en el siglo XVIII, el 23 de septiembre de 1718 se agregó:

- Uno y tercio de Aduana, que cobraba el Consulado de Sevilla con el nombre de "Lonja e Infantes"10; arbitrio que se recaudó hasta finales del año 1721, cuando un Real despacho ordenó a los contadores de la Aduana que lievaban la cuenta y razón del mismo, que cesasen en su cobranza, ya que se habia resuelto que su administración y manejo volviese de nuevo al Consulado.

Otro Real Despacho de 6 de marzo de 1719 , concedió a la ciudad, con el misno objeto, los arbitrios - que dejaron de percibirse en los inicios de la década de los años 40- de:

-6 reales en arroba de aguardiente.

-7 reales y medio en la arroba de mistela.

"A.H.M.C., Libro de Cabildo no 10.074 fols. 319 v., 327 v. - 330, y 338 v. 
El impuesto sobre estos productos se efectuaba para los que ingresasen en la ciudad destinados al propio consumo, o a la exportación con la salvedad de los que se enviaran a las Indias ${ }^{11}$.

Acerca del arbitrio de 1\% "moderno" de Aduana, ha de observarse que se le concedió a la ciudad, el 13 de octubre de 1710, para satisfacer diversos donativos que la misma había realizado al Rey. Por un Real Despacho de 10 de junio de 1719, el producto de este arbitrio se destinó a abonar las cantidades que se adeudaban de los créditos contraídos para los gastos que se produjeron en la defensa de la plaza en los años 1701 y 1702 . Otra Real Orden de 10 de febrero de 1722 mandó que su rendimiento se aplicase al cuidado de la salud pública, corriendo su percepción a cargo del Cabildo hasta que cesó la misma el 21 de enero de 1730, cuando José Patiño comunicó al Gobernador de la plaza que su producto se destinaría a la construcción en la Isla de León de los almacenes para la pólvora de la Marina que se levantarían en el sitio de la Cantera de la Isla de León. El propio Patiño conunicó, por Real Orden del 16 de febrero de 1732, que una vez terminada la construcción de estos depósitos, el producto de tal arbitrio se dedicaría a la obra de los cuarteles que se levantarían para la tropa de guarnición de la propia ciudad de Cádiz. En agosto de 1740 y con motivo de la peste que se detectó en Esmima y Argel, coyunturalmente sus rendimientos se dedicaron al resguardo de la salud pública.

La ampliación del $1 \%$ sobre entrada y salida de Aduana -excepto los comestibles- fue solicitada al Rey en 1702, después de que la ciudad representase al Gobernador la necesidad de hacer un muelle en la punta del baluarte de San Felipe hasta la peña de la Cruz, y otro desde el baluarte del Boquete a la bahia, y se tratase el asunto en cabildo general ${ }^{12}$.

El arbitrio del 1/2\% "moderno" de Aduana, que pagaban los géneros que marchaban y procedían de América, fue concedido también en el mismo Real Despacho del 13 de octubre de 1710 para pagar donativos, hasta que a partir de junio de 1715 su producto se aplicó a la obra del arrecife que discurría desde la Puerta de Tierra de la ciudad de Cádiz a la Alcantarilla de la Isla de León. Por la citada Real Orden de 16 de febrero de 1732, su rendimiento se destinó también a la fábrica de los cuarteles referidos.

\footnotetext{
"Para evitar fraudes, se decidió que tales derechos se pagasen cuando todos estos géneros entrasen en la ciudad con independencia de sus destinos, devolviéndose los importes de aquellos que se embarcaran para América.

${ }^{12}$ A.H.M.C., Libro de Cabildo ñ. 10.058, fols. 92 v.- 94 y 137.
} 
Estas imposiciones fueron administradas directamente por el Cabildo municipal gaditano hasta el 15 de diciembre de 1727, cuando se decidió establecer una Junta de Fortificaciones o de Murallas, compuesta de un Presidente -el Gobernador de la ciudad-, dos diputados capitulares, un ingeniero-director, un comisario ordenador, y un escribano de Cabildo, que se ocupó de su administración y manejo, y cuyas actuaciones comenzaron el 13 de febrero de 1728. Las cantidades eran asentadas en los libros propios de Cuenta de cargo y data de los caudales de arbitrios destinados a Murallas, y cada semana se remitía a la Secretaría de Estado de Guerra la situación de la caja, según un formulario en el que incluían las partidas de lo recibido y los gastos pagados. Estos estados de cuentas parciales se completaban con un estado general que se remitía al finalizar cada año.

A la Junta de Murallas se le concedió la facultad de sacar a un precio fijo e inferior al de mercado, de 18 rs. vn., el cahíz de cal de cada barco grande que arribase a Cádiz, y 1/2 cahíz en cada barco pequeño; lo que se unía a diversas exenciones en el pago de derechos que gozaron los materiales constructivos destinados a las fortificaciones.

\subsection{ARBITRIOS EXTRAORDINARIOS}

Cuando los arbitrios ordinarios no bastaron para atender a los gastos, se recurrió a formas extraordinarias de financiación, que no revistieron una importancia destacable hasta que se decidió acometer el gran proyecto de la Muralla del Sur.

En el año 1708, la reparación de las brechas que los temporales habían provocado en el paraje de la Escalerilla y en Puerto Chico se efectuó con el importe del alquiler de medio mes de las casas de toda la ciudad, salvo en aquellos casos en los que existían privilegios en contrario ${ }^{13}$. En 1719, el Cabildo municipal acordó sacar del arbitrio de la limpieza 2.000 pesos, con la condición de que fuesen reintegrados, para atender las reparaciones urgentes del muelle de desembarco ${ }^{14}$.

El 30 de Marzo de 1787 se aprobaron el proyecto y los presupuestos de reedificación de todo el frente de Vendaval de la ciudad de Cádiz, la muralla del Sur, según el plan de playa artificial diseñado por el ingeniero de Marina Tomás Muñoz, con un cómputo de cuatro años para construirla y un coste que se evaluó

${ }^{17}$ Ibídem, Libro de Cabildo $n^{\circ} .10 .064$, fols. $64 \mathrm{v}, \mathrm{y} 65$.

${ }^{14}$ Ibídem, Libro de Cabildo $n^{\circ}$. 10.075, f. 217. 
inicialmente en 19.880 .985 rs. vn. Y como los arbitrios de murallas entonces existentes resultaban claramente insuficientes para atender también a esta nueva obra, se añadieron a lo que ya recibía de manera ordinaria la Junta de Fortificaciones un conjunto de arbitrios extraordinarios. En un principio, las nuevas imposiciones fueron:

- Un $12 \%$ en la venta de las fincas, que se pagaria en cuatro años a un tercio cada uno; o un $10 \%$ si se abonaba de una sola vez. Pero con la condición de que los dueños no podrían elevar el precio de los alquileres.

- Un $3 \%$ anual en el producto de los arrendamientos de las casas, sin exceptuar las de comunidades religiosas, hospitales o fundaciones pías, por un tiempo de cuatro años, cuyo monto total se calculó que ascendería a 250 o 300.000 pesos $^{15}$. El Ayuntamiento propuso como alternativa a este impuesto, en primer lugar, un arbitrio de ocho cuartos en cada cuartillo de aguardiente y de los licores que en la ciudad se consumiesen por espacio de cinco años; lo que se rechazó ante la oposición presentada por la Secretaria de Estado de Hacienda. El $1^{\circ}$ de abril de 1788 se previno que se llevase a cabo el impuesto sobre las casas; y la orden fue reiterada el 14 de julio siguiente. La ciudad aducía, para no llevarlo a efecto, que poseía el privilegio de que no le fuese impuesta contribución alguna sobre las casas del vecindario, por una Real Cédula de 9 de septiembre de 1669, otorgada por la madre de Carlos II, al haber servido la ciudad con 70.000 escudos para urgencias del Real servicio. En esta concesión se había expresado que $n i$ por urgente necesidad ni con pretexto alguno de servicio, donativo, préstamo ni otro qualquiera, se habia de poder exijir ni cobrar contribución alguna de las casas de la ciudad ${ }^{16}$. En segundo lugar, el cabildo municipal planteó la aplicación de un nuevo derecho sobre todas las mercaderías que entrasen y saliesen por la Aduana, atendiéndose no al tamaño ni al valor, sino al peso bruto. Así se abonaría $1 / 2 \mathrm{rl}$. vn. por lo que pesase hasta 8 arrobas; $1 \mathrm{rl}$. vn. por lo que pasase de 8 y hasta $12 ; 2$ rs. vn. por lo que pesara entre 12 y 16 arrobas; y 3 rs. vn. por lo que superase las 16 . La Junta Suprema de Estado trató esta propuesta de nuevo arbitrio para subrogar el del 3 por \% sobre el alquiler de las casas en la sesión del 8 de septiembre de 1788; pero no se llegó a acuerdo alguno ya que se consideró

\footnotetext{
Is Ibídem, Libro de Cabildo $\mathrm{n}^{\circ}$. 10.144, fs, $44-46$.

16 En 1705 , se había pretendido cobrar otro derecho sobre las casas gaditanas, y la ciudad respondió con el mismo argumento, que fue aceptado, no llevándose a efecto la cobranza. Posteriormente, en 1708, con motivo de graves desperfectos en el amurallamiento, se quiso exigir de nuevo una contribución sobre las mismas. El Consejo de Castilla reconoció el privilegio de exención de que gozaba la ciudad y ordenó como alternativa que se tomase dinero prestado y a interés sobre los arbitrios del octavo en bota de vino y demás que se tenían reconocidos para tal fin.
} 
oportuno consultar a los Directores generales de Rentas y al Tribunal de la Contratación. Hasta el 23 de octubre de 1789 no se aceptó el recurso de la ciudad de Cádiz para que no tuviese efecto la imposición del $3 \%$ sobre los alquileres de casas para la obra de la muralla del Sur. Mas, considerándose que entre todos los arbitrios ya impuestos y los que se pudiesen imponer, éste del 3\% sería extraordinariamente productivo, y atendiéndose a la capacidad del Rey-que en uso de su facultad suprema podía anular los privilegios que se habían otorgado a cambio de servicios pecuniarios, al devolver la cantidad que por ellos se entregó-, se ordenó que de los caudales recibidos en el fondo vitalicio ya establecido se reintegrasen a la ciudad los referidos 70.000 escudos. Una Real Orden de 7 de abril de 1790 mandó restituir el importe del 3 por 100 durante cuatro años sobre los alquileres.

- Las tabernas, cervecerías, y tiendas de comestibles y de licores contribuirían con 40 rs. vn. al mes.

- Las casas de entretenimiento y recreo, como eran cafés, botillerías, mesas de billar y truco, bochas, pelota y raqueta, gallos, etc., pagarian mensualmente 60 rs. vn.

- La mitad de lo que sobrase de propios y del arbitrio anual del aguardiente y mistelas, que estaban estancados y destinados al enlosado de las calles.

- La tercera parte del impuesto que se exigía del vino para el empedrado y limpieza pública.

- El aumento del precio de las entradas de quienes concurriesen al teatro o Coliseo Español y otros espectáculos de comedias, "hasta alcanzar los precios usuales de Madrid".

- Los festejos de toros, durante el tiempo que se permitieron -y lo fueron hasta la víspera del miércoles de Ceniza del año 1790-, cuyas entradas equipararian el precio con las madrileñas.

Posteriormente, en agosto de 1789, y ante el desajuste tan enorme que siempre existió entre las previsiones de los gastos y los efectivamente realizados -en aquel momento se precisaban urgentemente unos $800.000 \mathrm{rs}$. vn.-, y dado que los arbitrios de murallas antiguos y modernos no alcanzaban, se establecieron otros nuevos recursos mientras durase esta obra.

- Todos los fondos de fortificación -salvo $300.000 \mathrm{rs}$. vn. que se asignaron para el cierre de la muralla del Norte y los necesarios enzulacados y otras reparaciones menores-; todo lo destinado al nuevo enlosado de la ciudad; 
y todo lo que se pudiese sacar de los arbitrios para la limpieza, salvo lo más imprescindible para su cuidado.

- 80 rs. vn. al mes por cada coche de rúa, argumentándose que el recinto de la ciudad de Cádiz era tan pequeño que no eran necesarios, debiéndose considerar consiguientemente como un objeto de lujo.

El 18 de diciembre del mismo año se prevenía a la Junta de Fortificaciones sobre las resoluciones que había tomado la Junta Suprema de Estado, facultándola para imponer nuevos impuestos para la obra de la Muralla del Sur:

- 10 pesos mensuales a cada tienda de las modistas extranjeras que había en la ciudad, entendiéndose por tales aquellas donde se hacen y se venden sombrerillos, bonetillos, cofias, guarniciones, y demás adornos mugeriles. De esta contribución quedaban libres las tiendas cuyos dueños fuesen españoles, o la de los extranjeros que hubiesen renunciado a tal fuero con el objeto de ser tratados como naturales.

- 6 u 8 mil pesos a la compañía denominada de aljameles o palanquines, mientras durase la obra.

- El sobrante de la contribución del alumbrado, que ascendía al año a 480.000 rs. vn., de los que sólo se gastaban 295.800. Y para sacar más partido a este impuesto, se determinó no encenderlo en las noches de luna, como se hacía en Madrid.

- Alguna imposición sobre los buques nacionales y extranjeros según sus toneladas, ya fuese con título de anclaje u otro parecido. Y sobre las personas que arribasen por mar de las costas vecinas, una contribución semejante al peazgo que se impuso por tierra sobre los carruajes; dejándose a criterio de la Junta de Fortificaciones las cantidades correspondientes.

Simultáneamente, se otorgaba permiso para la apertura del fondo vitalicio - del que se tratará más adelante-, para el que serviría de garantía el producto de los arvitrios antiguos y modernos, aplicados a costear la obra de la muralla del Sur, después de cubiertas sus propias obligaciones.

La Junta de Fortificaciones y el Gobernador de Cádiz representaron entonces al Rey para exponer las dificultades y los inconvenientes que encontraban para poner en prácticas estos nuevos impuestos, salvo el primero. En noviembre de 1790, el Ayuntamiento de Cádiz le recordaba los cuantiosos gastos que habian ocurrido hasta el momento y la insostenible presión que se ejercía sobre la población gaditana con motivo de esta carísima obra. Se especificaba que, en tal año, los gastos habían sobrepasado los 10.000 .000 rs. vn.; que eran 10.500 .000 
rs. vn. los que se habían pedido prestado hasta el presente a un 4 por ciento de interés anual -que era el mismo que redituaban los vales reales ${ }^{17}$; y que los réditos que habrían de pagarse de los $10.000 .000 \mathrm{ts}$. vn. del empréstito vitalicio, con un premio del 9 por ciento, ascendía cada año a 900.000 rs. vn. Así pues, sólo en el capítulo de los intereses, la Junta de Fortificaciones debía soportar cada año el pago a los capitalistas de 1.301 .900 rs. vn. por la deuda contraída. En consecuencia, y ante el agobio existente en la ciudad por tan enorme carga impositiva para las fortificaciones que soportaba el vecindario, el Cabildo municipal reclamó que no se creasen nuevas imposiciones, y que el peso de los derechos que hubieran de aplicarse para poder finalizar los trabajos en el frente del Sur lo soportase el comercio con América.

Se intentó que los gastos fuesen también sufragados por los pueblos vecinos; cosa conceptuada como justa por los gaditanos, ya que era Cádiz la que los defendía, fomentaba y enriquecía. De ahí que solicitasen del monarca que los mismos arbitrios que se pagaban en su ciudad sobre el vino, se extendiese a la Isla de León, Chiclana de la Frontera, Puerto Real, Puerto de Santa Maria, Rota -en los cuales existían fortificaciones que se habían construido y reparado con las contribuciones pagadas por el vecindario gaditano-, e incluso a Sanlúcar de Barrameda y Jerez de la Frontera..

Las corridas de toros fueron también otro de los medios a los que se recurrió para financiar las fortificaciones gaditanas, como se ha especificado más arriba. Estos espectáculos habían llegado a producir en concepto de impuestos para Cádiz más de 25.000 pesos anuales, hasta el momento de su prohibición. Ya en junio de 1765 se había otorgado el permiso Real a la Junta de Murallas para poder celebrar durante diez años doce corridas anuales de toros, cuyo producto se aplicó a la reparación de las ruinas padecidas en las murallas, para lo cual se celebró la pertinente contrata. En noviembre de 1790, cuando se buscaban denodadamente nuevos fondos que allegar para la muralla del Sur, el Ayuntamiento de la ciudad solicitó que se implantasen de nuevo, alegándose a favor de las mismas que proporcionaban un arbitrio seguro, voluntarisimo y aún deseado por los habitantes de Cádiz, quienes se veían obligados a desplazarse hasta el Puerto de Santa María y Jerez de la Frontera para presenciar las corridas. De aquí se pensaban obtener alrededor de $\operatorname{los} 400.000$ rs. vn. que faltarían al año para poder finalizar las obras.

En enero de 1792, se autorizaron 200 nuevas corridas de toros distribuidas en diez años, a veinte cada uno, en atención a las dificultades que existían para encontrar nuevos fondos con los que abonar el pago de los capitales que se habi-

${ }^{17}$ El interés usual, a la sazón, entre los comercjantes gaditanos era del medio por ciento al mes. 
an tomado. Sacadas a pública subasta y rematada por el mejor postor, éste tomó la obligación de satisfacer 30.145 rs. vn. y 17 mrs. por cada función, cuyo producto se destinó enteramente a reintegrar los préstamos que había efectuado el Consulado de Cádiz a la Junta de Fortificaciones. En junio de 1805 se habían celebrado 157 funciones -menos de las previstas, a causa de las guerras y epidemias que habían ocurrido-, restando 43 , que a razón del dinero referido, significaban 1.296. 261 rs. vn. y 17 mrs. La ciudad se dirigió al Rey señalando el perjuicio que se creaban a las obras de las Murallas de Cádiz, a raíz de la cédula Real de 10 de febrero de este año, que había prohibido en todo el reino las fiestas de toros y novillos de muerte ${ }^{18}$.

\section{3.- FONDOS VITALICIOS}

Se entiende por "fondo vitalicio", "fondo muerto" o "fondo perdido" al capital que se pone a rédito sobre la vida de alguien, bajo la condición de que una vez muerto aquel sobre cuya vida se impone, quede el capital a beneficio del que lo recibió y paga el rédito ${ }^{19}$.

En la sesión de 7 de diciembre de 1789, la Junta Suprema de Estado aprobó el establecimiento de un fondo vitalicio para la continuación de las obras de la Muralla del Sur, inicialmente de 8.000 .000 rs. vn., que fueron ampliados a 10.000.000 rs. vn. en la sesión de 11 de enero de 1790. El director de las obras lo había solicitado en octubre antecedente, pero elevándolo a 20.000 .000 rs. vn. La Junta Suprema facultó a la Junta de Fortificaciones de Cádiz para que, en caso de necesidad, aumentase dicho fondo, tomando la cantidad que sea necesaria para satisfacer todos los gastos de dicha obra hasta su total conclusion, bajo las mismas calidades y reglas con que desde el principio se estableció y abrió el citado fondo (sesión del 2 de agosto de 1791); como así se efectuó fijándose edictos anunciando al público la ampliación en 3.000 .000 rs. vn. Las acciones del fondo fueron limitadas inicialmente a $100.000 \mathrm{rs}$. vn. por personas, para ser luego incrementadas hasta los 300.000. En 1794 este fondo vitalicio llegaba a los 13.000 .000 rs. v11., cuyo interés al $9 \%$ importaba anualmente 1.170 .000 rs. vn.

\footnotetext{
"1" A.H.M.C., Libro de Cabildos n. 10.161, fol. 330.

${ }^{19}$ Sobre las rentas vitalicias en el siglo XVIII, remito a: MATILLA TASCÓN, Antonio: Las rentas vilalicias en el siglo XVIII. Inventario. Madrid, Ministerio de Cultura, 1980; y PIEPER, Renate: La Real Hacienda bajo Fernando VI y Carlos III (1753-I788). Madrid, Instituto de Estudios Fiscales, 1992, que trata acerca del Real Fondo Vitalicio creado en noviembre de 1769 (pp. 75-76).
} 
El recurso al fondo vitalicio también se pensó para las obras de la nueva población de San $\operatorname{Carlos}^{20}$. A finales de 1792, en una situación límite hasta el punto de que ni se cumplía con el pago a los asentistas y proveedores, y ni tan siquiera se podían despedir a los trabajadores de las actividades que se llevaban por administración, por falta de fondos con los que poder liquidarlos, la Junta Suprema de Estado resolvió la apertura de un fondo vitalicio por un valor de 30.000 .000 rs. vn., bajo las siguientes condiciones:

1) La admisión de capitales se distribuiría en cinco años, a razón de 6.000 .000 rs. vn. cada uno, comenzándose el $1^{\circ}$ de marzo de 1793.

2) Las acciones -que quedarían depositadas en la Tesorería del Departamento de Marina, donde se entregaría a los accionistas el resguardo competente- serían de 15.000 rs. vn., a un interés del $8 \%$ anual durante la vida del capitalista, a cuyo fallecimiento el fondo quedaría a favor de la Real Hacienda.

3) El Intendente del Departamento expediría los billetes a los capitalistas, ante el cual se subscribirían personalmente o por poder.

4) El pago de los intereses se aseguraba con la dotación anual ordinaria para las obras de 2.400 .000 rs. vn., a la que se unía la hipoteca de los terrenos reales que estaban demarcados para ser vendidos a los particulares en la misma nueva población.

5) Los subscriptores cobrarían sus intereses al final de cada año, cumplido desde la fecha de emisión de sus respectivos billetes por la Secretaría de la Intendencia, la cual libraría las pólizas que deberían ser presentadas en la Tesorería.

6) Dicha cobranza se podía efectuar con la presencia del interesado o de su apoderado, quien tenía que exhibir el poder, el billete, y la fe de vida de su causante.

7) Tanto el producto del fondo vitalicio, como el de la consignación de las obras, quedarían depositados en arca de tres llaves, de las cuales una tendría el Director de las obras, otra el Tesorero de Marina, y la tercera se hallaría en poder de quien eligiesen los capitalistas, que así tendrían seguridad del pago ${ }^{21}$.

\footnotetext{
2" El fondo perdido para las obras de San Carlos había sido ya propuesto, tratando el asunto la Junta Suprema de Estado en la sesión de 21 de febrero de 1791; y aunque pareció conveniente su adopción, se difirió hasta que se completase el fondo vitalicio ya abierto para la obra de la muralla del Sur.

${ }^{21}$ A.G.M., Arsenales-Población de San Carlos, año 1793.
} 
El establecimiento del fondo vitalicio para San Carlos resultó un fracaso. Dos meses después de iniciarse la recepción de capitales, únicamente se habían depositado 60.000 rs. vn., producto de 4 acciones, y hay constancia de que se subscribieran más hasta que en las condiciones pactadas con el asentista José Rodriguez para concluir las obras ya comenzadas en la misma nueva población, a finales de 1794 , figuró que 2.500 .000 rs. vn. de los que deberían pagársele, serían impuestos - una vez concluidos los trabajos- en acciones de este fondo perdido, pagadero al citado $8 \%$ de rédito anual ${ }^{22}$.

\section{4.- PRÉSTAMOS}

El crédito como mecanismo de financiación de la obra pública se puso en práctica muy tempranamente en el Cádiz del siglo XVIII, con motivo de la Guerra de Sucesión. En 1701, y ante la pronta necesidad de su defensa, la ciudad buscó --respondiendo con los arbitrios de murallas- 40.000 ducados ${ }^{23}$. También este mismo año se intentaron conseguir 100.000 escudos de plata, tomados sobre los arbitrios, ofreciendo la Cofradía del Señor de la Columna 4.100 pesos escudos a censo ${ }^{24}$. Igualmente se otorgó escritura sobre 1.000 doblones al 8 por ciento a favor de Pedro de Cepeda. Lo mismo se hizo con el marqués del Pedroso, en la cantidad de 1.000 doblones y a idéntico interés. Al año siguiente, Pedro Luis de Lila y Valdés prestó 500 pesos para las fortificaciones. En 1708 se trató en Cabildo de la ciudad de Cádiz la Real Provisión para tomar nuevos préstamos con los que atender las obras de las murallas, y se nombraron diputados para su ejecución ${ }^{25}$.

En 1719 el Ayuntamiento gaditano acordó solicitar de nuevo permiso al Rey para recibir 20.000 pesos a préstamos con el objeto de atender las obras urgentes de las murallas, incluyendo 4.000 que ofrecía el Cabildo Eclesiástico. Éstos se prestaron el 6 de octubre de tal año, con el fin de cerrar la muralla del Vendaval, antes de que los nuevos temporales del invierno destruyesen lo existente ${ }^{26}$.

Para la obra de la muralla del Sur y playa artificial se recurrió asimismo a los empréstitos. Por Real Orden comunicada en 30 de marzo de 1787, el Consulado de Cádiz se vio forzado a suministrar a la Junta de Fortificación 500.000 rs. vn., con el objeto de iniciarse las obras; cantidad ésta que sería rein-

\footnotetext{
${ }_{22}^{2}$ Ibidem, Arsenales-Construcciones, leg. 1794.

2. A.H.M.C, Libro de Cabildo $n^{\circ}$. 10.057, fols. 164 y 175.

${ }^{24}$ Ibiden, Libro de Cabildo n". 10.057, fols. 196 v., 237 a 241 v., 251 v.- 253 v. y 256.

${ }^{25}$ lbídem, Libro de Cabildo no. 10.081, fols. 180 y $180 \mathrm{v}, 206,218-219$, y 259.

${ }^{26}$ lbídem, Libro de Cabildos $n^{\circ}$. 10.075, fols. 330 - 331; y Libro de Cabildos n. 10.076, fols. 3 - 5 .
} 
tegrada según lo permitiesen los futuros fondos de la Junta de fortificaciones. Otra Real Orden de 22 de enero de 1788 obligó a entregar con el mismo fin 3.500 .000 rs. vn., procedentes de la Real Hacienda de lndias.

En 1791 el Consulado de Cádiz entregó a la Junta de Fortificaciones 6.710 .047 rs. vn. y $23 \mathrm{mrs}$., a devolver en cuatro años y medio, y a un interés de 4 por ciento anual. El aumento de los réditos del fondo vitalicio -en septiembre de este mismo año se había acordado fijar edictos públicos anunciando la ampliación del fondo vitalicio en 3.000 .000 rs. vn. más- hizo dificil reintegrar al Consulado los capitales e intereses pactados, por lo que se determinó dejar siempre para lo último el pago de los intereses del referido dinero que prestó el Consulado (sesión de la Junta Suprema de Estado de 26 de septiembre de 1791).

\section{5.- DONACIONES}

A finales de septiembre de 1788 se socorrió a las obras de la muralla del Sur de Cádiz con un 1.500.000 rs. vn., provenientes del Fondo de Encomiendas que se administraba y recaudaba a disposición del Rey para su libre administración.

Con motivo de la guerra entre España y la Francia de la Convención, declarada el 7 de mayo de 1793, llegaron donativos al Estado de todos lados. El ambiente favorable al enfrentamiento, fomentado por la Iglesia y la nobleza, había tomado cuerpo en particular desde que el 21 de enero de tal año se había guillotinado a Luis XVI. El conde de Buena Vista, coronel del Regimiento de Caballería de Voluntarios de la ciudad de La Habana, ofreció al Rey -por intermediación del Secretario de Estado y del Despacho Universal de Marina Antonio Valdés y Bazán- 60.000 rs. vn. El ofrecimiento fue admitido, y el dinero se entregó al Intendente de Marina de Cádiz por el marqués de Casa Enrile, ingresándose en la Tesorería del Departamento con destino a las obras de la nueva población de San Carlos. El hecho se anunció en la Gaceta y se notició al Secretario de Estado de Guerra, el conde de Campo Alange, para que se considerase como mérito del de Buena Vista en su carrera militar ${ }^{27}$.

${ }^{27}$ A.G.M., Arsenales-Nueva Población de San Carlos, año 1793. 


\section{6.- EJECUCIÓN DE TRABAJOS, A CAMBIO DE LA CONCESIÓN DE GRACIAS DIVERSAS}

Los apuros de la Real Hacienda, que fueron grandes y crecientes en la última década del Setecientos, propiciaron otro medio de financiación: el derivado de los ofrecimientos de los particulares para realizar obras para el Estado muy por debajo de sus costes, recibiendo en contrapartida gracias de diversos tipos.

Así, José Rodríguez --vecino de la ciudad de Cádiz, negociante y comerciante con Indias-, quien aprovisionaba de maderas para la Marina y los trabajos de la muralla del Sur, y era asentista en las obras de la Nueva Población de San Carlos, se ofreció a levantar en ésta -en enero de 1792- las casas del Capitán General y del Intendente por algo más de la mitad de lo presupuestado; en conformidad con los proyectos aprobados, ahorrando a la Real Hacienda 1.116.525 rs. vn., a cambio de Ios siguientes favores reales:

1) Que a su hijo José se le otorgara una cruz pensionada de Carlos III, con opción a la primera vacante, cuando estas obras estuviesen fuera de cimientos.

2) Que a su hijo Severino, a la sazón capitán del Regimiento de la Puebla de los Angeles, en Nueva España, se le concediese la agregación de coronel, una vez que los edificios estuviesen concluidos ${ }^{28}$.

Las propuestas fueron aceptadas y, en conformidad a lo pactado, las gracias fueron otorgadas. El 1 de agosto de 1792, el conde de Aranda participaba a Antonio Valdés la concesión de la Cruz de la Real Orden Española de Carlos III a José Rodríguez Carvallo, con opción a pensión de las que quedasen libres pertenecientes al Ministerio de Marina ${ }^{29}$.

Como la fórmula dio resultados, el asentista efectuó nuevas proposiciones, con motivo del levantamiento del cdificio de la Contaduría y Tesorería de Marina, que se presupuestaron en 2.214 .436 rs. vn. José Rodríguez. se comprometía a construitlo, según lo programado, por 990.000 rs. vn., impetrando por el ahorro resultante de $1,224.436 \mathrm{rs}$. vn. dos gracias:

1) Título de Castilla, libre de lanzas y media anata, para si y sus sucesores.

\footnotetext{
${ }^{2}$ Este hijo debió ser el que en 1788 servia de cadete, y su padre solicitó entonces empleo de oficial en una compañia de un regimiento de Infantería a cambio de rebajar $7 \mathrm{rs}$. vл. en cada codo de la maderá de pino que se utilizó en las obras de las murallas del Sur, dejándolo en 35 ya colocado a pie de obra; lo que significaba un ahorro de al menos $210,000 \mathrm{rs}$. vn.

1" A.G.M., Arsenales-Construcciones, año 1793.
} 
2) Permiso para transportar en una fragata de su propiedad al puerto de Veracruz 2.000 balones de papel y 3.000 quintales de azogue. $\mathrm{O}$, como alternativa, el embarque de 2.000 tercios de ropas extranjeras con el mismo destino, sin las obligaciones del equivalente nacional.

Mas, no obstante la recomendación por parte del Director de las obras de que se aceptase la proposición, ésta fue rechazada en la corte, al considerarse desproporcionados los beneficios que obtendría la Real Hacienda con las gracias solicitadas; muy en particular la consecución del título nobiliario por estos medios. Mas la penuria era tal, que en el mismo documento en el que se rechazaban las propuestas, se invitaba a Rodríguez a que efectuara otras ofertas al respecto.

En enero de 1793 un nuevo ofrecimiento de Rodríguez incluía levantar la Contaduría y Tesorería de Marina por 1.400 .000 rs. vn, pagaderos en tres plazos iguales al finalizar los años 1793,1794 y 1795, y se comprometía a erigir totalmente gratis las vecinas casas de Tesoreros y Academia de pilotos, a cambio de varios beneficios, siendo los dos más importantes:

1) Que a su hijo Severino se le otorgase agregación de coronel con el correspondiente sueldo en España, tal como lo tenía concedido en América ${ }^{30}$.

2) Que a su hijo Nicolás se le concediese la graduación y sueldo de Comisario de Provincia de Marina, cuando los edificios se hallase fuera de cimientos ${ }^{31}$.

Debido al poco éxito que tuvo el establecimiento del fondo vitalicio de 2.000.000 de pesos para invertirlo en las obras de San Carlos, y puesto que éstas no podían continuarse con la escasez de medios que había, dado que las consignaciones ordinarias estaban muy retrasadas, se decidió -en enero de 1794- dar por contrata todos los trabajos que en aquel momento estaban iniciados. Tras un largo proceso de ofertas presentadas por diversos asentistas, y de contraofertas efectuadas por la administración, en octubre del mismo año se alcanzó un acuerdo con el mismo José Rodríguez, el cual como premio a las ventajas que procuraba a la Real Hacienda en las condiciones estipuladas -en total un ahorro de algo más de 3.000.000 rs. vn. en lo presupuestado- fue beneficiado con las gracias que siguen:

1) Ser declarado primer poblador de la población de San Carlos.

\footnotetext{
"3 Tal grado y sueldo de coronel, con agregación al Regimiento de Infanteria de España, fue concedido a Severino el $1^{\circ}$ de agosto de 1795.

"El nombramiento de Nicolás como Comisario de Provincia graduado fue emitido en San Lorenzo el 25 de noviembre de 1793 . El sueldo correspondiente era de 12.000 rs. vn. anuales.
} 
2) Obtener un Título de Castilla, libre de lanzas y media anata para sí, sus hijos y sucesores, bajo la denominación de "Conde del Parque".

3) Lograr que su hijo José, ya caballero de la Real Orden de Carlos IIl, con opción a la primera vacante de pensión -correspondiente a la Marinaque se produjese, tomara posesión de la misma sin esperarse a ello ${ }^{32}$.

4) Alcanzar para su hijo Nicolás, ya entonces Comisario de Provincia de Marina, la promoción al grado de Comisario Real de Guerra de la misma Marina en propiedad ${ }^{33}$.

5) Recibir en exclusiva todos los géneros excluidos del arsenal de La Carraca, salvo aquéllos que ya estuviesen contratados y por el tiempo que el convenio durase, por término de cinco años y según el precio en que se evaluasen.

6) Obtener el permiso para sacar 500.000 pesos fuertes, para efectuar pagos al extranjero con total libertad de derechos.

Lo expresado en segundo, tercero y cuarto lugar fueron evaluadas en 1.310 .400 rs. vn., de los cuales 450.000 correspondían al título nobiliario ${ }^{34}$.

En otras ocasiones, los perjuicios económicos que se habían derivado de haber asentado obras con el Estado fueron esgrimidos como argumentos para la obtención de favores reales. Por ejemplo, el que fuera asentista del desmonte y terraplenado de la nueva población de San Carlos, el citado Francisco Zimbrelo, al solicitar en 1783 de la Secretaría de Estado de Gracia y Justicia un título de Castilla, argumentaba entre sus méritos para lograrlo los perjuicios que había sufrido con tal asiento, en particular su dilación ya que el contratista consideraba que lo que se podía haber finalizado en dos años largos se hallaba en el octavo y aún sin concluir ${ }^{35}$.

\footnotetext{
"2 José comenzỏ a percibir los 4.000 rs. un. anuales de la Tesorería de Marina a partir de $1^{\circ}$ de enero de 1796.

"Se llevó a efecto el 23 de octubre de 1795.

${ }^{14}$ A.G.M., Arsenales-Construcciones, antos $1794-1795$.

${ }^{15}$ Los trabajos de desmonte, terraplenado y acopio de los materiales de construcción resultantes comenzaron el 2 de enero de 1779 y no finalizaron hasta el 2 de mayo de 1788 .
} 